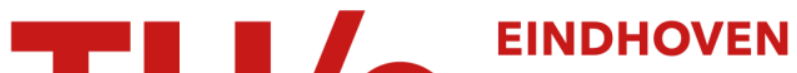 \\ UNIVERSITY OF \\ TECHNOLOGY
}

\section{Biological imaging and sensing with multiresponsive microgels}

Citation for published version (APA):

Zhang, Q. M., Wang, W., Su, Y., Hensen, E., \& Serpe, M. J. (2016). Biological imaging and sensing with multiresponsive microgels. Chemistry of Materials, 28(1), 259-265.

https://doi.org/10.1021/acs.chemmater.5b04028

DOI:

10.1021/acs.chemmater.5b04028

Document status and date:

Published: 01/01/2016

Document Version:

Publisher's PDF, also known as Version of Record (includes final page, issue and volume numbers)

Please check the document version of this publication:

- A submitted manuscript is the version of the article upon submission and before peer-review. There can be important differences between the submitted version and the official published version of record. People interested in the research are advised to contact the author for the final version of the publication, or visit the $\mathrm{DOI}$ to the publisher's website.

- The final author version and the galley proof are versions of the publication after peer review.

- The final published version features the final layout of the paper including the volume, issue and page numbers.

Link to publication

\section{General rights}

Copyright and moral rights for the publications made accessible in the public portal are retained by the authors and/or other copyright owners and it is a condition of accessing publications that users recognise and abide by the legal requirements associated with these rights.

- Users may download and print one copy of any publication from the public portal for the purpose of private study or research.

- You may not further distribute the material or use it for any profit-making activity or commercial gain

- You may freely distribute the URL identifying the publication in the public portal.

If the publication is distributed under the terms of Article 25fa of the Dutch Copyright Act, indicated by the "Taverne" license above, please follow below link for the End User Agreement:

www.tue.nl/taverne

Take down policy

If you believe that this document breaches copyright please contact us at:

openaccess@tue.nl

providing details and we will investigate your claim. 


\title{
Biological Imaging and Sensing with Multiresponsive Microgels
}

\author{
Qiang Matthew Zhang, ${ }^{\dagger}$ Wenda Wang, ${ }^{\dagger}$ Ya-Qiong Su, ${ }^{\ddagger}$ Emiel J. M. Hensen, ${ }^{\ddagger}$ and Michael J. Serpe*, \\ ${ }^{\dagger}$ Department of Chemistry, University of Alberta, Edmonton, Alberta, Canada T6G 2G2 \\ ${ }^{\ddagger}$ Eindhoven University of Technology, Department of Chemical Engineering and Chemistry, Schuit Institute of Catalysis, Inorganic \\ Materials Chemistry Group, P.O. Box 513, 5600 MB, Eindhoven, The Netherlands
}

\section{Supporting Information}

ABSTRACT: Multiresponsive spiropyran-modified poly $(\mathrm{N}$ isopropylacrylamide)-based microgels were synthesized and their response to temperature; UV, visible, and near-infrared radiation; $\mathrm{pH}$; and $\mathrm{Cu}^{2+}$ was investigated. The responses were a result of the spiropyran groups undergoing a reversible isomerization/reaction from a neutral to a charged form. The isomerization process was investigated via experiment and theory. The two-photon excited fluorescence of the spiropyran-modified microgels was also characterized, and their ability to be used to image live cells was determined. Finally, optical devices (etalons) were fabricated using the spiropyranmodified microgels, and the ability of the devices to change

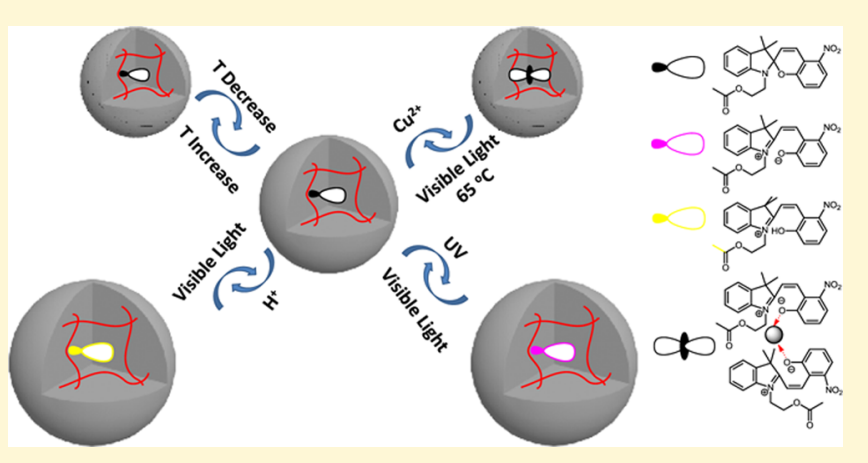
color in response to the above-mentioned stimuli was also investigated. We found that the microgel's responsivity was retained in the etalon, which yielded color tunable devices and sensors. This investigation illustrates the versatility of pNIPAm-based microgels and microgel-based etalons and showcases the clear utility of such devices for remote actuation, color tunable optics, sensing, and remotely triggered drug delivery systems.

\section{INTRODUCTION}

The ability of natural systems to sense, respond, and adapt to environmental conditions has both fascinated and inspired philosophers and researchers alike for ages. Inspired by nature, "smart" materials have been developed in the lab that can respond in defined ways to environmental or external stimuli $^{1-4}$ such as temperature, ${ }^{5} \mathrm{pH}^{6}{ }^{6}$ light, ${ }^{7,8}$ magnetic field, ${ }^{9}$ electric field, ${ }^{10}$ ions, ${ }^{11,12}$ enzymes, ${ }^{2,13}$ and specific organic compounds. ${ }^{14}$ Polymeric materials are particularly attractive due to the variety of monomers available that allow their chemistry to be easily tuned. For example, certain monomers can be chosen that result in polymers with specific mechanical properties, biocompatibility, and the ability to swell, shrink, or bend in response to a wide variety of environmental stimuli. $^{15-18}$ Of all stimuli-responsive polymers, temperatureresponsive poly $(N$-isopropylacrylamide) (pNIPAm) is the most well-known and well studied, ${ }^{19}$ exhibiting a lower critical solution temperature (LCST) at $32{ }^{\circ} \mathrm{C} .{ }^{20}$ Consequently, by altering the temperature of pNIPAm in water, its solubility can be tuned; e.g., pNIPAm transitions from hydrophilic (soluble, extended state) to hydrophobic (insoluble, collapsed state) as the LCST is exceeded.

PNIPAm-based polymer networks can also be generated by cross-linking the pNIPAm chains. This can yield macroscopic hydrogels, or hydrogel particles with diameters on the micron to nano scale. Specifically, pNIPAm-based hydrogel particles (microgels) can be synthesized to have diameters on the order of $100 \mathrm{~nm}$ to several micrometers. ${ }^{21-24}$ They can be used for sensing and actuation, ${ }^{25}$ catalyst supports, ${ }^{26}$ drug delivery, ${ }^{27}$ and enzyme nanocapsules. ${ }^{28}$ In order to expand the utility of the above-mentioned microgels, it is necessary to render them responsive to a number of different stimuli, i.e., individual microgels that can respond to multiple stimuli (multiresponsive). Multiresponsive microgels could open up second-generation applications of microgels with useful combined chemical and physical properties.

Our group's research program has focused on the development of novel microgels, and investigating their use as sensors, artificial muscles, and drug delivery motifs. ${ }^{29-33}$ In an effort to make our materials even more functional and responsive, we show here that multiresponsive pNIPAm-based microgels could be synthesized by incorporation of spiropyran (SP) into the microgel structure. SP is a unique molecule that exhibits "responsivity" to a number of different stimuli. For example, it has been shown that SP can undergo $\mathrm{C}$ (spiro)-O bond cleavage upon UV light irradiation, ${ }^{34} \mathrm{pH}$ changes, ${ }^{35}$ ultrasound exposure, ${ }^{36}$ mechanical force, ${ }^{37,38}$ electric fields, ${ }^{39}$ and in the presence of certain metal ions. ${ }^{40,41}$ Here, we investigate the microgel's response to ultraviolet (UV) and visible light, $\mathrm{pH}$, temperature, and copper ion $\left(\mathrm{Cu}^{2+}\right)$, as depicted in Scheme la. Specifically, SP's C(spiro)-O bond can be cleaved by UV light exposure, and at low $\mathrm{pH}(<4)$. During the process, SP isomerizes from a colorless, nonplanar, closed and neutral form to the colored, planar, open and charged merocyanine form

Received: October 16, 2015

Revised: November 30, 2015

Published: December 17, 2015 
Scheme 1. (a) Schematic Illustration of the Various Responses Predicted from Spiropyran-Modified Microgels, and the Corresponding Molecular Structures on the Right. (b) Schematic of the Etalon Structure and Its Response ${ }^{a}$

(a)

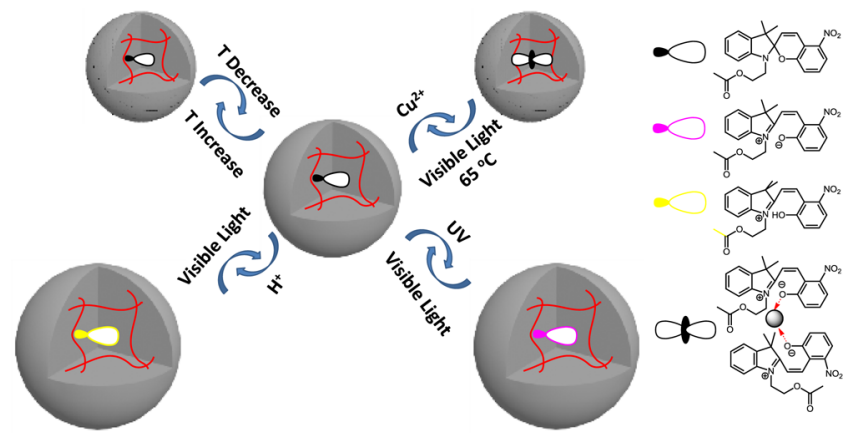

(b)

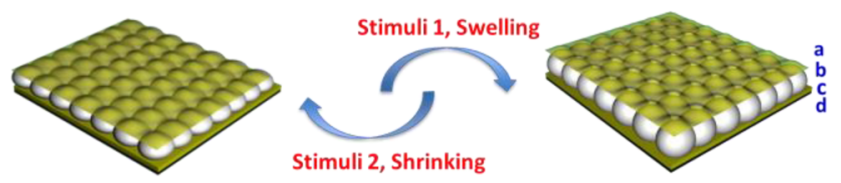

${ }^{a}$ In the right cartoon: (a, c) Au layers; (b) microgel layer (defines the distance between two Au layers); and (d) substrate.

(MC). ${ }^{42}$ The charged MC structure of SP increases the microgel's inner osmotic pressure and hydrophilicity, which results in microgel swelling, as shown in Scheme 1a. MC can also be triggered to reform SP by visible light-the SP-MC-SP transition is reversible over many cycles without performance loss. ${ }^{42}$ Additionally, $\mathrm{Cu}^{2+}$ is able to cleave the $\mathrm{C}($ spiro $)-\mathrm{O}$ bond into $\mathrm{MC}$, which can bind $\mathrm{Cu}^{2+}$ and cross-link the microgels phenoxide anions with a 2:1 stoichiometry. Finally, the SP-modified microgels are responsive to near-IR (NIR) light. This is a result of SP-to-MC isomerization triggered by exposure to $780-840 \mathrm{~nm}$ NIR wavelengths. Interestingly, MC also exhibits two-photon excited fluorescence, absorbing low energy NIR, and emitting visible light at $590 \mathrm{~nm}$. This property is especially important for biological imaging because low energy excitation is gentle on biological tissues and cells. ${ }^{43}$ Furthermore, the NIR excitation wavelengths are capable of penetrating relatively deeply into skin, allowing fluorescence to be excited in living systems. In the current work, we used breast cancer cells (MCF-7) to demonstrate the biological imaging capabilities of our microgels.

\section{RESULTS AND DISCUSSION}

\subsection{Synthesis and Characterization of SP-Containing}

Microgels. In order to investigate the effect of chemical structure on SP behavior, two SP monomers (with and without a nitro group) were synthesized in four steps, as detailed in the Supporting Information (SI). The effect of the nitro group on SP isomerization was investigated via experiment and theory. SP containing a nitro group is denoted as SP (or MC)-a, whereas the SP without the nitro group is denoted as SP (or $\mathrm{MC}$ )-b (Figure S1). Microgels were synthesized by free radical precipitation polymerization of $\mathrm{N}$-isopropylacrylamide (NIPAm), acrylic acid (AAc), and $N, N^{\prime}$-methylenebis(acrylamide) (BIS), following standard protocols (SI). ${ }^{4-46}$ SP monomers were incorporated into microgels via an esterification reaction between SP's hydroxyl group and the microgel's carboxylic acid (SI). After the esterification reaction, the $\mathrm{pH}$ of the microgel solution changed from 4.2 to 6.8 , which is indicative of the acrylic acid being transformed into the ester group. The amount of unreacted AAc was determined by titration with $\mathrm{NaOH}$ using methyl red as an indicator-we determined that the unreacted AAc amount was below 3\%. These microgels (MG) are denoted as MG-SP (or MC)-a (or -b). We determined the diameter of the microgels via dynamic light scattering (DLS) (Figures S2 and S3), which revealed hydrodynamic diameters of $880 \mathrm{~nm}$ for $\mathrm{MG}, 770 \mathrm{~nm}$ for MG$\mathrm{SP}-\mathrm{a}$, and $760 \mathrm{~nm}$ for MG-SP-b at $30{ }^{\circ} \mathrm{C}$.

The decrease of the hydrodynamic diameter after the esterification reaction was attributed to the increased microgel hydrophobicity by replacing the AAc with SP. The LCST of the microgels was also determined, and these microgels exhibited an LCST of $32.5{ }^{\circ} \mathrm{C}$ for MG and $30.5{ }^{\circ} \mathrm{C}$ for MG-SP-a/b in DI water. The decrease of the LCST was also attributed to increased hydrophobicity of microgels by SP modification. Since pNIPAm-based microgels are more sensitive to stimuli near their LCST, most of the following investigations were completed at $30^{\circ} \mathrm{C}$. Transmission electron microscope (TEM) images of the resultant microgels can be seen in Figure 1. From analysis of 30 microgels in the image, we determined that the dried microgels had an average diameter of $\sim 400 \mathrm{~nm} \pm 1.5 \%$. (a)

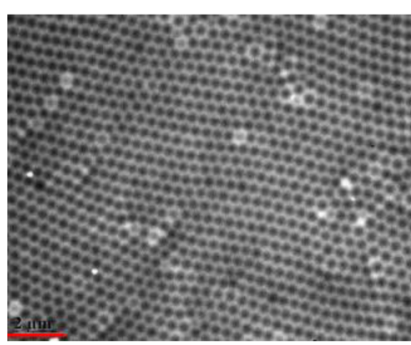

(b)

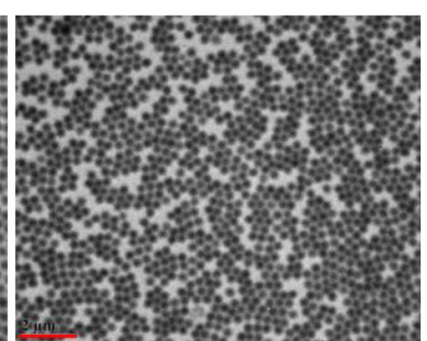

Figure 1. TEM images of (a) MG and (b) MG-SP-a. The scale bar is 2 $\mu \mathrm{m}$.

2.2. Etalon Construction. Microgel-based optical devices (etalons) were first reported by our group in 2010.30,31 Since then, they have been shown to be extremely versatile, exhibiting visual color, and multipeak reflectance spectra, which can be tuned as a function of many different stimuli (Scheme 1b). ${ }^{32,44-46}$ We have also shown that they are able to act as drug delivery devices, and artificial muscles (among other things). ${ }^{30,32,47}$ In short, etalons are constructed by painting a concentrated microgel solution on a Au-coated glass substrate, followed by copious rinsing with deionized water to remove microgels not directly attached to the Au. Finally, the microgel layer was dried, and a subsequent layer of Au was deposited on the microgel layer. The structure of the resultant etalons was investigated using scanning electron microscopy (SEM), and the images can be seen in Figure S4. The SEM images revealed a single microgel layer, and a structure typical of microgel-based etalons. The optical properties of the devices can be predicted by eq 1

$$
m \lambda=2 n d \cos \theta
$$

where $m$ (an integer) is the order of a reflected wavelength $(\lambda)$, $\lambda$ is the wavelength of reflected light of a given peak order, $n$ is the refractive index of the dielectric layer, $d$ is the distance 
between the two Au layers that is defined by the thickness of the microgel layer ( $b$ in Scheme $1 b$ ), and $\theta$ is the angle of incident light relative to the etalon normal. Therefore, the positions of the peaks in the reflectance spectra (and hence the device color) depend on the distance between two Au layers and the refractive index of microgels (at a single observation angle). ${ }^{30}$ For our devices, the optical properties depend primarily on the distance between the two Au layers.

2.3. Temperature Responsivity. To confirm the basic responsivity and function of the etalons, initial experiments focused on characterizing the etalon response to temperature (i.e., thermoresponsivity). Etalons were immersed in water for this investigation; the resulting reflectance spectra are shown in Figure 2. As can be seen, a reflectance spectrum with a peak at

(a)

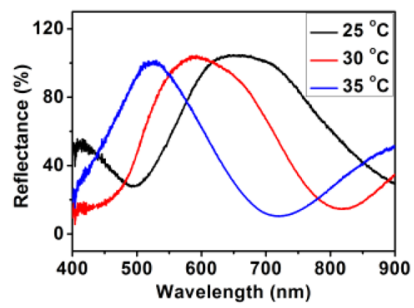

(b)

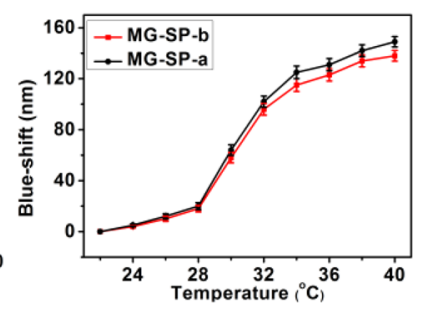

Figure 2. (a) Reflectance spectra for an etalon composed of MG-SP-a in water at the indicated temperatures. (b) Peak shifts as a function of temperature for indicated etalons. Each point is the average from three repeated experiments with a single device, while the error bars indicate standard deviation.

$650 \mathrm{~nm}$ at $25{ }^{\circ} \mathrm{C}$ was observed. When the temperature was increased to $30^{\circ} \mathrm{C}$, the peak exhibited a blue shift of $60 \mathrm{~nm}$, while it exhibited an additional $\sim 70 \mathrm{~nm}$ shift $(130 \mathrm{~nm}$ total shift) when the temperature was increased to $35^{\circ} \mathrm{C}$. These peak shifts are a direct result of the thermoresponsivity of the pNIPAm-based microgels, which collapse at elevated temperature, decreasing the distance between the etalons two $\mathrm{Au}$ layers. This can be predicted from eq 1 .

2.4. UV Responsivity and Simulation. Since the basic thermoresponsivity of the pNIPAm microgel-based devices was confirmed, the response of the microgels and microgel-based etalons to UV irradiation was subsequently characterized. As can be seen in Figure 3a, when SP is exposed to UV light $(\sim 360 \mathrm{~nm})$, it undergoes an SP-MC isomerization, resulting in a change of the microgel solution color from colorless to pink. Examination of the pink solution with a UV spectrophotometer showed a new absorbance band centered at $540 \mathrm{~nm}$, corresponding to the open MC form of SP (Figure $3 \mathrm{~b}) .^{40}$ Exposure to ambient light for $20 \mathrm{~min}$ at room temperature caused the peak to disappear (Figure 3b), consistent with the known photolytic reversion to the closed SP form. ${ }^{40}$ In order to further understand the adsorption of MC at $540 \mathrm{~nm}$, we used a multiscale theoretical method to predict the light adsorption spectrum of MC. The absorption spectrum was simulated at a B3LYP/6-311+G(d,p) level in the Gaussian 09 package. ${ }^{48}$ In our calculations, the basis set $6-311+\mathrm{G}(\mathrm{d}, \mathrm{p})$ was used for $\mathrm{C}, \mathrm{N}$, $\mathrm{O}$, and $\mathrm{H}$ atoms with the B3LYP functional. ${ }^{49}$ As shown in Figure 3, the position of the predicted absorption peak (537 $\mathrm{nm}$ ) is in good agreement with the experimentally observed absorption peak $(535 \mathrm{~nm})$. This indicates that simulation at the B3LYP/6-311+G(d,p) level is acceptable. The strong absorption of $\mathrm{MC}$ at $537 \mathrm{~nm}$ in Figure $3 \mathrm{c}$ was attributed to the (a)

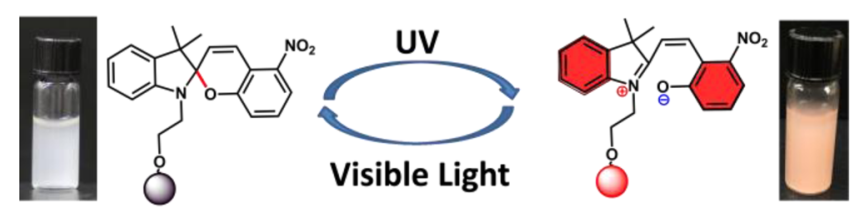

(b)

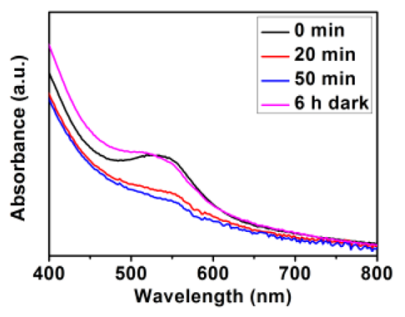

(d)

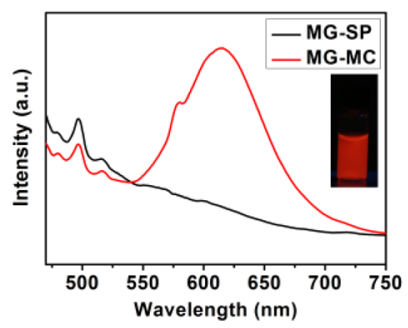

(c)

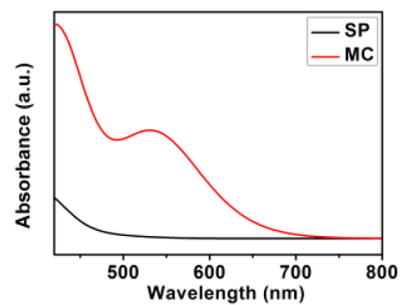

(e)

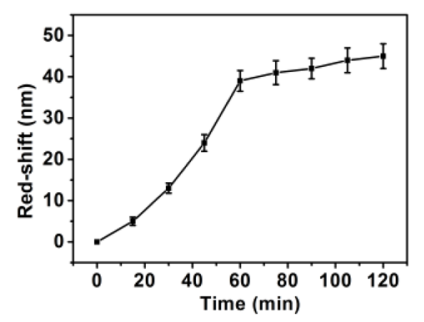

Figure 3. (a) SP-MC isomerization triggered by UV and visible light. (b) UV absorption curves of MG-MC-a after exposure to visible light for the indicated times $(20$ and $50 \mathrm{~min}$ ) and after in the dark for $6 \mathrm{~h}$. (c) Simulated UV absorption curves of MG-MC-a. (d) Fluorescence spectra of MG-SP-a and MG-MC-a (405 nm excitation). Inset: optical image of MG-MC-a exposed to UV light. (e) Peak shifts of MG-SP-a etalon as a function of time at $30^{\circ} \mathrm{C}$. Each point is the average from three repeated experiments with a single device, while the error bars indicate standard deviation.

electronic transition from HOMO (NO- $\sigma$ and $\mathrm{CO}-\pi$ ) to LUMO $\left(\mathrm{NC}-\pi^{*}\right)$. The fluorescence of MG-MC was also investigated. A strong red fluorescence was observed by exciting $\mathrm{MC}$ at $405 \mathrm{~nm}$, while monitoring the emission between 570 and $670 \mathrm{~nm}$. As can be seen in Figure 3d, MC showed a strong emission band at $620 \mathrm{~nm}$, while MG-SP produced no such red fluorescence. Because of the difference of fluorescence between $\mathrm{SP}$ and MC, the isomerization process can be monitored via observation of fluorescence intensity. For this investigation, 480 $\mathrm{nm}$ light was used to excite MC fluorescence while also triggering the MC-to-SP transition. As shown in Video 1 (a red light filter was placed in front of the camera to collect red fluorescence from MC), MG-MC-a showed strong fluorescence, which was "quenched" as a function of time due to $\mathrm{MC}$ isomerization to SP. Fluorescence was fully quenched after 3 $\mathrm{min}$, indicating full isomerization of MC to SP.

The reversible isomerization also causes a change of the microgel diameter as a result of the charged MC form transitioning to the neutral SP form. As can be seen in Figure S5, the diameter of the microgels decreased from 810 to 770 $\mathrm{nm}$ as a result of the MC-SP isomerization process. We propose that the MG-MC microgels are large in diameter due to their hydrophilicity and the charged state generating an inner osmotic pressure, which results in water entering the microgels and microgel swelling. For comparison, the response of 
pNIPAm-based microgels (without SP) to UV irradiation was investigated at the same conditions, which did not exhibit any size change after UV exposure (Figure S6), indicating that the change in diameter of MG-SP-a resulted from isomerization of SP to MC. The change in diameter of the microgels as a result of the isomerization process can also be characterized using the etalon structure. The MG-SP-a etalon's reflectance peak exhibits a red shift of $45 \mathrm{~nm}$ at $30{ }^{\circ} \mathrm{C}$ after exposure to UV light, as shown in Figure 3e. The red shift observed in the reflectance spectrum was attributed to the increase in microgel size as a result of the SP-MC isomerization process. When the etalon was exposed to visible light, the reflectance peak shifts back to its initial position within $2 \mathrm{~h}$. This is due to the isomerization of $\mathrm{MC}$ form back to SP form with reformation of the $\mathrm{C}$ (spiro)-O bond. The response/reversibility for each etalon was repeated 5 times without a noticeable change in its response. For comparison, etalons fabricated using MG without SP were prepared and tested, which did not exhibit any observable response after exposure to UV light (Figure S7). This further indicates that the shifts in the peaks of the reflectance spectra are a result of SP-MC isomerization. Finally, etalons composed of MG-SP-b microgels were fabricated and tested under the same conditions as above, which did not exhibit any spectral shift after exposure to UV (Figure S8). This result indicates that UV light cannot trigger SP-MC isomerization for MG-SP-b.

In order to understand why SP-a and SP-b behave differently, the activation energy of the $\mathrm{C}$ (spiro) -O bond of SP-a and SP-b was calculated using Gaussian 09 at the B3LYP/6-311+G(d,p) level. In their ground states, SP-a and SP-b have similar $\mathrm{C}$ (spiro) $-\mathrm{O}$ bond lengths (2.26 ̊̊ for SP-a and $2.29 \AA$ for SP$\mathrm{b})$, and SP-a and SP-b need to overcome energy barriers of 12.35 and $15.33 \mathrm{kcal} / \mathrm{mol}$ to break the $\mathrm{C}$ (spiro)-O bond and generate the $\mathrm{MC}$ form, respectively (Figure S9). According to the Arrhenius equation

$$
k=A \mathrm{e}^{-E_{\mathrm{a}} /(R T)}
$$

where $k$ is rate constant, $T$ is absolute temperature, $A$ is preexponential factor, $E_{\mathrm{a}}$ is activation energy, and $R$ is universal gas constant. The rate constant ratio of SP-a to SP-b is 163, indicating that the nitro group accelerates the isomerization speed by 163 . Thus, all of following work was completed using MG-SP-a.

2.5. $\mathrm{pH}$ Responsivity. It has been reported that the SP-MC isomerization occurs at low $\mathrm{pH}^{35}$ generating phenol and quaternary ammonium groups with a color change from colorless to yellow, ${ }^{47}$ as illustrated in Figure $4 \mathrm{a}$. Therefore, the response of MG-SP-a to $\mathrm{pH}$ was also characterized. We showed that, in acidic solution, the SP group of the microgels is in the protonated $\mathrm{MC}$ form $(\mathrm{MCH})$ and exhibits a yellow color. After exposure to visible light, the yellow color of microgels disappeared and microgels become colorless, indicating isomerization of the $\mathrm{MCH}$ form to the closed-ring SP form. This isomerization process is believed to release a proton (Figure $4 \mathrm{a}$ ), which can be observed as a $\mathrm{pH}$ change. To investigate this further, a certain amount of MG-SP-a was dissolved in water $\left(\mathrm{pH}=4.2\right.$ with a molar ratio of SP to $\left.\mathrm{H}^{+}=1.5: 1\right)$. After $2 \mathrm{~h}$ in the dark, the $\mathrm{C}$ (spiro)-O bond was broken, and the resultant phenate groups combined with protons to generate $\mathrm{MCH}$ with a $\mathrm{pH}$ change from 4.2 to 5.3. Once the solution was exposed to visible light for $1 \mathrm{~h}$, the $\mathrm{pH}$ of the solution returned to 4.2 (a 10-fold change in $\mathrm{H}^{+}$concentration). This was attributed to proton release from the isomerization of $\mathrm{MCH}$ to SP triggered (a)

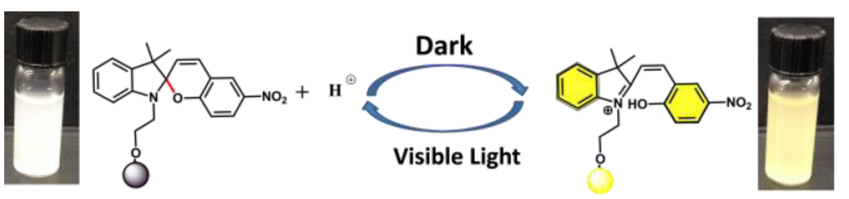

(b)

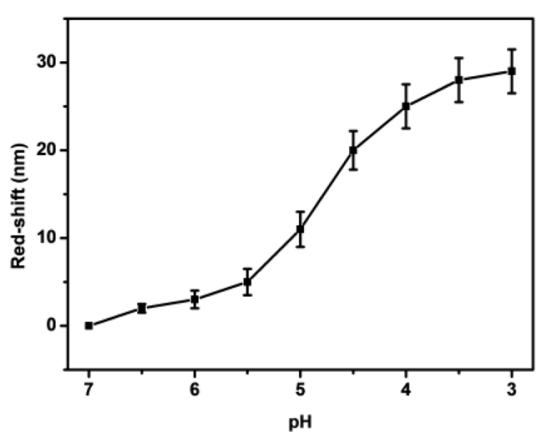

Figure 4. (a) Reversible SP-MC-SP isomerization triggered by $\mathrm{H}^{+}$and visible light. (b) Etalon reflectance peak shift as a function of $\mathrm{pH}$; each point is the average from three repeated experiments with a single device, while the error bars indicate standard deviation.

by visible light. The diameter change of these microgels was also monitored using DLS, which revealed that the diameter of the microgels increased from 770 to $800 \mathrm{~nm}$ when MG-SP transitioned to MG-MCH (Figure S10). According to the above results, we hypothesized that etalons composed of MGSP-a should be $\mathrm{pH}$ responsive, swelling at low $\mathrm{pH}$ from the charge generation. When the solution $\mathrm{pH}$ was decreased from 7 to 3, the observed reflectance peaks shifted $29 \mathrm{~nm}$ to higher wavelength (Figure 4b). After that, the etalons were regenerated by exposure to visible light. A total of three individual etalons were investigated, all exhibiting similar properties. An etalon fabricated using MG was also used as a control experiment, which did not exhibit any spectrum shift in response to $\mathrm{pH}$ change (Figure S11).

2.6. $\mathrm{Cu}^{2+}$ Responsivity. In a subsequent experiment, the response of MG-SP-a to $\mathrm{Cu}^{2+}$ was investigated. It has been reported that SP-MC isomerization of the small monomers can be triggered by $\mathrm{Cu}^{2+}$, and exposure to visible light can regenerate $\mathrm{SP}$ with expulsion of the $\mathrm{Cu}^{2+} \cdot{ }^{50}$ Recently, nanoporous frameworks with SP have been synthesized and used for $\mathrm{Cu}^{2+}$ release. ${ }^{40}$ The mechanism of $\mathrm{Cu}^{2+}$ response is shown in Figure 5a. In the process, MG-SP-a was dissolved into $\mathrm{CuCl}_{2}$ solution (ratio of $\mathrm{SP}$ to $\mathrm{Cu}^{2+}$ is $2: 1$ ). After $2 \mathrm{~h}$ in the dark, MG-SP-a transitions from colorless to red and the microgels aggregate-this is indicative of the isomerization of the SP form to the MC form. The aggregation is a result of $\mathrm{Cu}^{2+}$ coordinating with the phenoxide anions in a $2: 1$ stoichiometry. The aggregates can be seen in the bottom of the right tube in Figure 5a. The $\mathrm{Cu}^{2+}$ concentration of the solution was investigated by atomic adsorption spectrophotometry, and the result showed that $35 \% \mathrm{Cu}^{2+}$ was incorporated

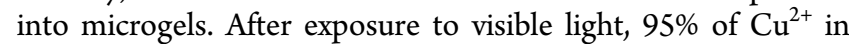
microgels was released. For comparison, pNIPAm microgels without SP were also tested at the same conditions and were able to absorb $4.5 \% \mathrm{Cu}^{2+}$. Figure $5 \mathrm{~b}$ shows the dependence of the position of the etalon's reflectance peak as a function of $\mathrm{Cu}^{2+}$ concentration in water. Spectra exhibit blue shifts as the 
(a)

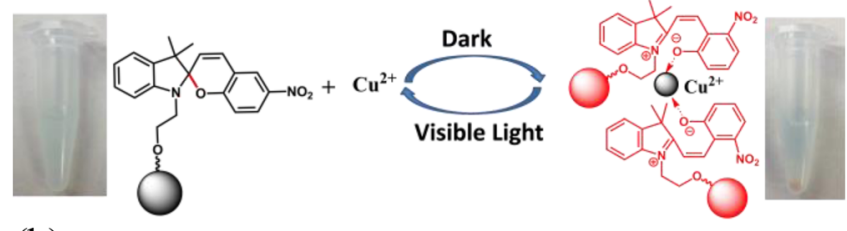

(b)

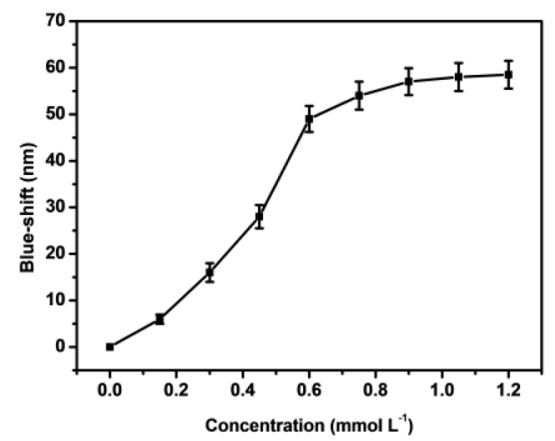

Figure 5. (a) SP-MC isomerization triggered by $\mathrm{Cu}^{2+}$ and visible light. (b) Etalon reflectance peak shift as a function of $\mathrm{Cu}^{2+}$ concentration; each point is the average from three repeated experiments on a single device, while the error bars indicate standard deviation.

solution concentration of $\mathrm{Cu}^{2+}$ was increased. $\mathrm{Cu}^{2+}$ acts like a cross-linking site, resulting in deswelling of microgels and blue shifts of etalon spectra. As can be seen in Figure $5 b$, etalon spectra exhibited a total blue shift of $59 \mathrm{~nm}$, as the $\mathrm{Cu}^{2+}$ concentration increases from 0 to $1.2 \mathrm{mmol} \mathrm{L}^{-1}$. Therefore, the device can be used for quantitative analysis of $\mathrm{Cu}^{2+}$. Etalons composed of just MG did not exhibit a significant spectral response to $\mathrm{Cu}^{2+}$ (Figure S12).

2.7. NIR Responsivity and Biological Imaging. Lastly, we investigated the response of microgels to NIR exposure $(800 \mathrm{~nm})$ and used the microgels for biological imaging (bioimaging). It has been reported that SP can be triggered to transform to MC upon exposure to $800 \mathrm{~nm}$ radiation (NIR); ${ }^{34}$ this wavelength was also capable of inducing fluorescence in the wavelength range from 520 to $640 \mathrm{~nm}$ (Figure 6a). In order to use this material for bioimaging, small diameter microgels (SMG) with diameters of $150 \mathrm{~nm}$ (determined by TEM (Figure 6b)) were synthesized (see the SI), which was named as SMG-SP(MC)-a. It has been reported that nanoparticles within the diameter range of $100-200 \mathrm{~nm}$ can undergo endocytosis, and be taken up by cells. ${ }^{51}$ Once cells take up the SMG-SP-a via endocytosis, the fluorescence images of cells can be obtained due to the fluorescence of MC upon exposure to $800 \mathrm{~nm}$ light. Figure $6 c, d$ shows bright-field and two-photon fluorescence images, respectively, of breast cancer cell line (MCF-7) after their incubation overnight in a $1 \times 10^{-5} \mathrm{~g} \mathrm{~mL}^{-1}$ SMG-SP-a solution. Under $800 \mathrm{~nm}$ two-photon excitation, these cells exhibited red fluorescence due to two-photon excited fluorescence of SMG-MC-a. For comparison, the microscope and two-photon excited fluorescence images of MCF-7 without exposure to SMG-SP-a were obtained, which did not show fluorescence. This clearly shows the ability of SPMG to be used for biological imaging (Figure S13).

\section{CONCLUSION}

To summarize, we developed microgels that exhibit responses to multiple stimuli; i.e., they are able to respond by swelling or shrinking in response to exposure to light (UV and visible), (a)

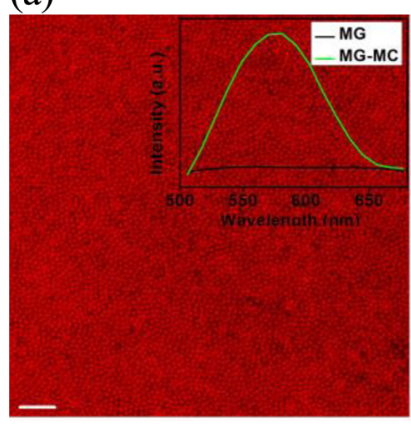

(b)

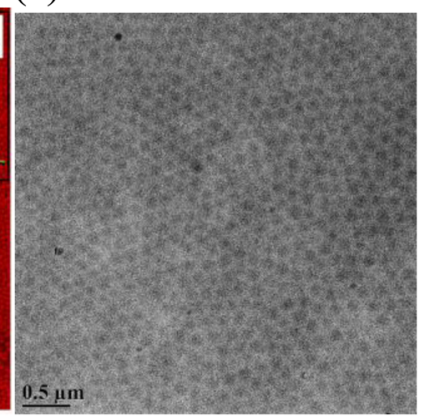

(c)

(d)
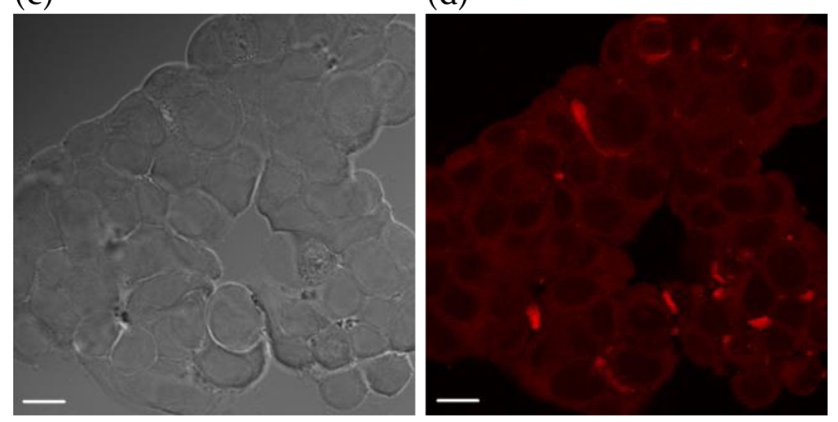

Figure 6. (a) Fluorescence microscope image of MG-MC-a (800 nm excitation); scale bar is $4 \mu \mathrm{m}$. Inset: Fluorescence spectra of $\mathrm{MG}$ and MG-MC-a (800 nm excitation) in the solid state. (b) TEM image of SMG-MC-a. (c) Bright-field microscopy image of MCF-7 cells; scale bar is $20 \mu \mathrm{m}$. (d) Fluorescence microscopy image of MCF-7 after incubation in SMG-SP-a; scale bar is $20 \mu \mathrm{m}$.

solutions of various $\mathrm{pHs}$, and exposure to $\mathrm{Cu}^{2+}$. Etalon devices were fabricated using these microgels, which are capable of changing their optical properties in response to the application of a number of different stimuli. This behavior can be used for sensing applications, as well as for remote actuation and triggered drug/small molecule delivery. Furthermore, we showed that the synthesized microgels have the ability to undergo two-photon fluorescence, which can be exploited for biological imaging applications. This investigation not only showcases the versatility of pNIPAm-based microgel chemistry, and how it can be manipulated to achieve very complex responsivities, but it also shows the versatility of the etalon construct. This chemical/functional diversity, combined with the biological imaging applications, make these materials highly valuable for myriad applications.

\section{ASSOCIATED CONTENT}

\section{S Supporting Information}

The Supporting Information is available free of charge on the ACS Publications website at DOI: 10.1021/acs.chemmater.5b04028.

Information on materials used and experimental details, microgel synthesis protocols, chemical structure for SP monomers, dynamic light scattering measurements of microgel diameters, scanning electron microscope images, reflectance spectra for etalon devices, potential energy diagrams for $\mathrm{C}-\mathrm{O}$ bond breaking, and cell images (PDF)

Video showing the fluorescence of MG-MC-a and its quenching when $\mathrm{MC}$ isomerizes to SP (AVI) 


\section{AUTHOR INFORMATION}

\section{Corresponding Author}

*E-mail: michael.serpe@ualberta.ca. Fax: +1 780492 8231. Tel: +17804925778.

\section{Notes}

The authors declare no competing financial interest.

\section{ACKNOWLEDGMENTS}

M.J.S. acknowledges funding from the University of Alberta (the Department of Chemistry and the Faculty of Science), the Natural Sciences and Engineering Research Council of Canada (NSERC), the Canada Foundation for Innovation (CFI), the Alberta Advanced Education \& Technology Small Equipment Grants Program (AET/SEGP), Grand Challenges Canada, and IC-IMPACTS. Q.M.Z. acknowledges financial support through an Alberta Innovates Technology Futures (AITF) Postdoctoral Fellowship.

\section{REFERENCES}

(1) Zhai, L. Stimuli-responsive Polymer Films. Chem. Soc. Rev. 2013, 42, 7148-7160.

(2) Maitz, M. F.; Freudenberg, U.; Tsurkan, M. V.; Fischer, M.; Beyrich, T.; Werner, C. Bio-responsive Polymer Hydrogels Homeostatically Regulate Blood Coagulation. Nat. Commun. 2013, 4, 21682175.

(3) Stuart, M. A. C.; Huck, W. T. S.; Genzer, J.; Muller, M.; Ober, C.; Stamm, M.; Sukhorukov, G. B.; Szleifer, I.; Tsukruk, V. V.; Urban, M.; Winnik, F.; Zauscher, S.; Luzinov, I.; Minko, S. Emerging Applications of Stimuli-responsive Polymer Materials. Nat. Mater. 2010, 9, 101113.

(4) Weder, C. Mechanochemistry Polymers React to Stress. Nature 2009, 459, 45-46.

(5) Kehrle, J.; Höhlein, I. M. D.; Yang, Z.; Jochem, A.-R.; Helbich, T.; Kraus, T.; Veinot, J. G. C.; Rieger, B. Thermoresponsive and Photoluminescent Hybrid Silicon Nanoparticles by Surface-initiated Group Transfer Polymerization of Diethyl Vinylphosphonate. Angew. Chem., Int. Ed. 2014, 53, 12494-12497.

(6) Onyango, J. O.; Chung, M. S.; Eng, C.-H.; Klees, L. M.; Langenbacher, R.; Yao, L.; An, M. Noncanonical Amino Acids to Improve the $\mathrm{pH}$ Response of $\mathrm{pHLIP}$ Insertion at Tumor Acidity. Angew. Chem., Int. Ed. 2015, 54, 3658-3663.

(7) Maity, C.; Hendriksen, W. E.; van Esch, J. H.; Eelkema, R. Spatial Structuring of A Supramolecular Hydrogel by Using a Visible-light Triggered Catalyst. Angew. Chem., Int. Ed. 2015, 54, 998-1001.

(8) Ube, T.; Ikeda, T. Photomobile Polymer Materials with Crosslinked Liquid-Crystalline Structures: Molecular Design, Fabrication, and Functions. Angew. Chem., Int. Ed. 2014, 53, 1029010299.

(9) Kwok, S. W.; Morin, S. A.; Mosadegh, B.; So, J. H.; Shepherd, R. F.; Martinez, R. V.; Smith, B.; Simeone, F. C.; Stokes, A. A.; Whitesides, G. M. Magnetic Assembly of Soft Robots with Hard Components. Adv. Funct. Mater. 2014, 24, 2180-2187.

(10) Ying, X.; Wang, Y.; Liang, J.; Yue, J.; Xu, C.; Lu, L.; Xu, Z.; Gao, J.; Du, Y.; Chen, Z. Angiopep-Conjugated Electro-responsive Hydrogel Nanoparticles: Therapeutic Potential For Epilepsy. Angew. Chem., Int. Ed. 2014, 53, 12436-12440.

(11) Grigoryev, A.; Sa, V.; Gopishetty, V.; Tokarev, I.; Kornev, K. G.; Minko, S. Wet-spun Stimuli-Responsive Composite Fibers with Tunable Electrical Conductivity. Adv. Funct. Mater. 2013, 23, 59035909.

(12) Kuroki, H.; Tokarev, I.; Nykypanchuk, D.; Zhulina, E.; Minko, S. Stimuli-Responsive Materials with Self-healing Antifouling Surface via 3D Polymer Grafting. Adv. Funct. Mater. 2013, 23, 4593-4600.

(13) Omichi, M.; Asano, A.; Tsukuda, S.; Takano, K.; Sugimoto, M.; Saeki, A.; Sakamaki, D.; Onoda, A.; Hayashi, T.; Seki, S. Fabrication of Enzyme-Degradable and Size-Controlled Protein Nanowires Using
Single Particle Nano-fabrication Technique. Nat. Commun. 2014, 5, 3718-3726.

(14) Ge, J.; Yin, Y. Responsive Photonic Crystals. Angew. Chem., Int. Ed. 2011, 50, 1492-1522.

(15) Therien-Aubin, H.; Wu, Z. L.; Nie, Z. H.; Kumacheva, E. Multiple Shape Transformations of Composite Hydrogel Sheets. J. Am. Chem. Soc. 2013, 135, 4834-4839.

(16) Pan, G. Q.; Guo, Q. P.; Ma, Y.; Yang, H. L.; Li, B. ThermoResponsive Hydrogel Layers Imprinted with RGDS Peptide: A System for Harvesting Cell Sheets. Angew. Chem., Int. Ed. 2013, 52, 69076911.

(17) Li, Y.; Gao, G. H.; Lee, D. S. Stimulus-Sensitive Polymeric Nanoparticles and Their Applications As Drug and Gene Carriers. Adv. Healthcare Mater. 2013, 2, 388-417.

(18) Jaspers, M.; Dennison, M.; Mabesoone, M. F. J.; MacKintosh, F. C.; Rowan, A. E.; Kouwer, P. H. J. Ultra-Responsive Soft Matter From Strain-Stiffening Hydrogels. Nat. Commun. 2014, 5, 5808-5816.

(19) Dimitrov, I.; Trzebicka, B.; Müller, A. H. E.; Dworak, A.; Tsvetanov, C. B. Thermosensitive Water-Soluble Copolymers with Doubly Responsive Reversibly Interacting Entities. Prog. Polym. Sci. 2007, 32, 1275-1343.

(20) Schild, H. Poly (N-isopropylacrylamide): Experiment, Theory and Application. Prog. Polym. Sci. 1992, 17, 163-249.

(21) Seiffert, S. Small But Smart: Sensitive Microgel Capsules. Angew. Chem., Int. Ed. 2013, 52, 11462-11468.

(22) Yue, M.; Hoshino, Y.; Ohshiro, Y.; Imamura, K.; Miura, Y. Temperature-Responsive Microgel Films as Reversible Carbon Dioxide Absorbents in Wet Environment. Angew. Chem., Int. Ed. 2014, 53, 2654-2657.

(23) Brown, A. C.; Stabenfeldt, S. E.; Ahn, B.; Hannan, R. T.; Dhada, K. S.; Herman, E. S.; Stefanelli, V.; Guzzetta, N.; Alexeev, A.; Lam, W. A.; Lyon, L. A.; Barker, T. H. Ultrasoft Microgels Displaying Emergent Platelet-like Behaviours. Nat. Mater. 2014, 13, 1108-1114.

(24) Stuart, M. A. C.; Huck, W. T.; Genzer, J.; Müller, M.; Ober, C.; Stamm, M.; Sukhorukov, G. B.; Szleifer, I.; Tsukruk, V. V.; Urban, M.; Winnik, F.; Zauscher, S.; Luzinov, I.; Minko, S. Emerging Applications of Stimuli-Responsive Polymer Materials. Nat. Mater. 2010, 9, 101113.

(25) Li, Y. Y.; Zhou, S. Q. Facile One-Pot Synthesis of Organic DyeComplexed Microgels for Optical Detection of Glucose at Physiological pH. Chem. Commun. 2013, 49, 5553-5555.

(26) Wu, S.; Dzubiella, J.; Kaiser, J.; Drechsler, M.; Guo, X.; Ballauff, M.; Lu, Y. Thermosensitive Au-PNIPA Yolk-Shell Nanoparticles With Tunable Selectivity For Catalysis. Angew. Chem., Int. Ed. 2012, 51, 2229-2233.

(27) Mura, S.; Nicolas, J.; Couvreur, P. Stimuli-Responsive Nanocarriers for Drug Delivery. Nat. Mater. 2013, 12, 991-1003.

(28) Smith, M. H.; Lyon, L. A. Tunable Encapsulation of Proteins Within Charged Microgels. Macromolecules 2011, 44, 8154-8160.

(29) Islam, M. R.; Li, X.; Smyth, K.; Serpe, M. J. Polymer-Based Muscle Expansion and Contraction. Angew. Chem., Int. Ed. 2013, 52, 10330-10333.

(30) Sorrell, C. D.; Serpe, M. J. Reflection Order Selectivity of ColorTunable Poly (N-isopropylacrylamide) Microgel Based Etalons. Adv. Mater. 2011, 23, 4088-4092.

(31) Sorrell, C. D.; Carter, M. C.; Serpe, M. J. Color Tunable Poly (N-Isopropylacrylamide)-co-Acrylic Acid Microgel-Au Hybrid Assemblies. Adv. Funct. Mater. 2011, 21, 425-433.

(32) Zhang, Q. M.; Xu, W.; Serpe, M. J. Optical Devices Constructed from Multiresponsive Microgels. Angew. Chem., Int. Ed. 2014, 53, 4827-4831.

(33) Li, X.; Serpe, M. J. Understanding and Controlling the Selffolding Behavior of Poly (N-isopropylacrylamide) Microgel-based Devices. Adv. Funct. Mater. 2014, 24, 4119-4126.

(34) Lai, J.; Zhang, Y.; Pasquale, N.; Lee, K. B. An Upconversion Nanoparticle with Orthogonal Emissions Using Dual NIR Excitations for Controlled Two-way Photoswitching. Angew. Chem., Int. Ed. 2014, $53,14419-14423$. 
(35) Tatum, L. A.; Foy, J. T.; Aprahamian, I. Waste Management of Chemically Activated Switches: Using A Photoacid to Eliminate Accumulation of Side Products. J. Am. Chem. Soc. 2014, 136, 1743817441.

(36) Potisek, S. L.; Davis, D. A.; Sottos, N. R.; White, S. R.; Moore, J. S. Mechanophore-Linked Addition Polymers. J. Am. Chem. Soc. 2007, 129, 13808-13809.

(37) Sottos, N. R. Polymer Mechanochemistry: Flex, Release and Repeat. Nat. Chem. 2014, 6, 381-383.

(38) Davis, D. A.; Hamilton, A.; Yang, J.; Cremar, L. D.; Van Gough, D.; Potisek, S. L.; Ong, M. T.; Braun, P. V.; Martínez, T. J.; White, S. R.; Moore, J. S.; Sottos, N. R. Force-Induced Activation of Covalent Bonds in Mechanoresponsive Polymeric Materials. Nature 2009, 459, $68-72$.

(39) Wang, Q.; Gossweiler, G. R.; Craig, S. L.; Zhao, X. CephalopodInspired Design of Electro-mechano-chemically Responsive Elastomers for On-demand Fluorescent Patterning. Nat. Commun. 2014, 5, 4899-4908.

(40) Kundu, P. K.; Olsen, G. L.; Kiss, V.; Klajn, R. Nanoporous Frameworks Exhibiting Multiple Stimuli Responsiveness. Nat. Commun. 2014, 5, 3588-3597.

(41) Liu, D.; Chen, W.; Sun, K.; Deng, K.; Zhang, W.; Wang, Z.; Jiang, X. Resettable, Multi-readout Logic Gates Based on Controllably Reversible Aggregation of Gold Nanoparticles. Angew. Chem., Int. Ed. 2011, 50, 4103-4107.

(42) Klajn, R. Spiropyran-Based Dynamic Materials. Chem. Soc. Rev. 2014, 43, 148-184.

(43) Valeur, B.; Berberan-Santos, M. N. Molecular Fluorescence: Principles and Applications; John Wiley \& Sons: Chichester, U.K., 2012.

(44) Zhang, Q. M.; Li, X.; Islam, M. R.; Wei, M.; Serpe, M. J. Light Switchable Optical Materials from Azobenzene Crosslinked Poly (Nisopropylacrylamide)-Based Microgels. J. Mater. Chem. C 2014, 2, 6961-6965.

(45) Zhang, Q. M.; Ahiabu, A.; Gao, Y.; Serpe, M. J. CO ${ }_{2}$-Switchable Poly (N-isopropylacrylamide) Microgel-Based Etalons. J. Mater. Chem. C 2015, 3, 495-498.

(46) Zhang, Q. M.; Berg, D.; Mugo, S. M.; Serpe, M. J. LipaseModified $\mathrm{pH}$-Responsive Microgel-Based Optical Device for Triglyceride Sensing. Chem. Commun. 2015, 51, 9726-9728.

(47) Sumaru, K.; Kameda, M.; Kanamori, T.; Shinbo, T. Reversible and Efficient Proton Dissociation of Spirobenzopyran-Functionalized Poly (N-isopropylacrylamide) in Aqueous Solution Triggered by Light Irradiation and Temporary Temperature Rise. Macromolecules 2004, 37, 7854-7856.

(48) Frisch, M.; Trucks, G.; Schlegel, H. B.; Scuseria, G.; Robb, M.; Cheeseman, J.; Scalmani, G.; Barone, V.; Mennucci, B.; Petersson, G.; et al. Gaussian 09, Revision A.02; Gaussian. Inc.: Wallingford, CT, 2009; 200

(49) Becke, A. D. Density-functional thermochemistry. III. The role of exact exchange. J. Chem. Phys. 1993, 98, 5648-5652.

(50) Winkler, J. D.; Deshayes, K.; Shao, B. Photodynamic Transport of Metal Ions. J. Am. Chem. Soc. 1989, 111, 769-770.

(51) Kulkarni, S. A.; Feng, S.-S. Effects of Particle Size and Surface Modification on Cellular Uptake and Biodistribution of Polymeric Nanoparticles for Drug Delivery. Pharm. Res. 2013, 30, 2512-2522. 